M.D. Sharpe MD, A.M. Lam MD, J.F. Nicholas MD, D.C. Chung MD, R. Merchant MD, W. Alyafi MD, R. Beauchamp MD

\title{
Correlation between integrated evoked EMG and respiratory function following atracurium administra- tion in unanaesthetized humans
}

In six healthy volunteers, integrated evoked electromyography (IEEMG) measured in response to ulnar nerve stimulation was correlated with respiratory function - tidal volume $(V T)$, forced vital capacity $(F V C)$, forced expiratory volume in one second $\left(F E V_{1}\right)$, maximum negative inspiratory pressure (NIP), hand grip ( $H G)$ and head-lift during steady-state infusion of subparalytic doses of atracurium. Studies were carried out as train-of-four $T_{4} / T_{1}=0.2$ and $T_{4} / T_{1}=0.6$. When $T_{4} / T_{1}=0.2$, all subjects had difficulty with swallowing and phonation, none could sustain any head-lift and HG was 26 per cent of control. However, VT was normal, FVC was 80 per cent, FEV, was 82 per cent, and NIP was 50 per cent of control. $A T T_{4} / T_{1}=0.6$, all assessments of peripheral strength were normal, and all respiratory measurements were not significantly different from control, except for NIP which was 73 per cent of control $(P<$ $0.05)$. We conclude that an IEEMG of 0.6, recorded from the hypothenar muscles, in unanaesthetized subjects is consistent with near normal respiratory function.

\section{Key words}

MEASUREMENT TECHNIQUES: electromyography; NEUROMUSCULAR RELAXANTS: atracurium; LUNG: function, inspiratory pressure, FVC.

Department of Anacsthesia, St. Joseph's Hospital, University of Western Ontario, London, Canada and Department of Anesthesiology, University of Washington, Seattle, Washington.

Address correspondence to: Dr. A. M. Lam, Department of Anesthesiology, Harborview Medical Center, 325 Ninth Avenue, Scattle, WA 98104.

This research project was partly supported by an equipment grant from Burroughs Wellcome Company of Canada.
Pendant une perfusion d'atracurium, nous avons mesuré simultanément, la réponse électromyographique (IEEMG) à une stimulation du nerf cubital, le volume courant (VC), la capacité vitale $(\mathrm{CV})$, le volume expiratoire maximal en une seconde (VEMS), la pression inspiratoire négative maximale (PINM), la force de préhension (FP) et l'élévation de la tête de six volontaires bien portant. Lorsque le $T_{4} / T_{1}$ du train-de-quatre était de 0,2 , tous avaient des problèmes de déglutition et d'élocution, aucun ne pourvait garder la tête levée et la FP n'équivalait qu'à 26 pour cent de sa valeur contrôle. Pourtant le $V C$ était normal, et la CV était à 80 pour cent, le VEMS à 82 pour cent et la PINM à 50 pour cent du contrôle. Avec un $T_{4} / T_{1}$ de 0,6 , la force des muscles périphériques était normale de même que les mesures de mécanique respiratoire sauf la PINM, à 73 pour cent du contrôle. Donc, avec un IEEMG de 0.6 à l'éminence hypothénar, la fonction respiratoire des sujets conscients est quasiment normale.

Neuromuscular blocking agents are routinely utilized in general anaesthesia to facilitate tracheal intubation and provide adequate relaxation for surgical procedures. Because neuromuscular weakness may lead to hypoventilation and/or upper airway obstruction, not infrequent complications observed in the recovery room, it is important that any residual neuromuscular blockade following a surgical procedure be detected and adequately reversed. ${ }^{1,2}$ Electrical stimulation of a peripheral nerve with subsequent observation of the mechanical or electromyographic response of its innervated muscle helps to determine the degree of neuromuscular blockade during administration of muscle relaxants. ${ }^{3-6}$ Furthermore, correlations between train-of-four and tetanic stimulation and variables of respiratory function have been established. ${ }^{7-9}$ However, an inexpensive and reliable, quantitative monitor of mechanical twitch response is as yet 
unavailable, and the intraoperative utilization of the peripheral nerve stimulator must, therefore, rely on subjective appraisal of the muscular response to nerve stimulation and the assessment may overestimate the actual degree of return of neuromuscular funciton. ${ }^{9}$ With the advent of integrated evoked electromyography (IEEMG), ${ }^{10-14}$ however, an accurate and quantitative assessment of neuromuscular blockade can be performed at the bedside and minimize the possibility of observer error. Previous studies have demonstrated that differences exist between electromyographic and mechanical twitch response, ${ }^{13,14}$ and the correlation between IEEMG and respiratory function has not been studied. Accordingly, we assessed the correlation between IEEMG with variables of respiratory function and peripheral motor strength in seven healthy volunteers following administration of subparalytic doses of atracurium.

\section{Methods}

With approval from the Institutional Ethics Committee on Human Research, seven healthy, unpremedicated, nonsmoking male volunteers, aged 26-47 years and receiving no medications, were studied in the supine position. Using the Datex 221 NMT monitor (Puritan-Bennett), IEEMG's were recorded with surface electrodes over the hypothenar muscles in response to train-of-four (TOF) supramaximal stimuli delivered to the ulnar nerve via surface electrodes at a frequency of $2 \mathrm{~Hz}$ every ten seconds. The NMT monitor displays the twitch depression from control $\left(\mathrm{T}_{1} / \mathrm{Tc}\right)$, and the TOF ratio $\left(\mathrm{T}_{4} / \mathrm{T}_{1}\right)$ continuously. The supramaximal stimulus was achieved with gradual increase of the stimulus intensity as preliminary studies had indicated that this manoeuvre minimizes discomfort.

TABLE I Anthropometric characteristics

\begin{tabular}{lcc}
\hline & Mean \pm SEM & Range \\
\hline Age (yr) & $35 \pm 3$ & $26-47$ \\
Height (cm) & $175 \pm 4$ & $165-188$ \\
Weight (kg) & $75 \pm 6$ & $60-98$ \\
\hline
\end{tabular}

Following recording of a stable control IEEMG, and allowing the subjects to be conditioned to the nose clip and mouthpiece, the following respiratory variables were measured using a Collins spirometer: tidal volume (VT), forced vital capacity (FVC), forced expiratory volume in one second $\left(\mathrm{FEV}_{1}\right)$ and maximum negative inspiratory pressure (NIP) (with a Bourne aneroid pressure gauge). In addition, peripheral muscle strength was measured using a modified hand-grip dynamometer (HG), ${ }^{15}$ and the ability to sustain head-lift for five seconds and protrude the tongue were assessed. All variables were measured in duplicate to ensure reproducibility and the results were averaged for statistical computations.

After administration of atropine (0.3-0.4 mg) to reduce secretions, atracurium, $0.03 \mathrm{mg} \cdot \mathrm{kg}^{-1}$ was given and followed with a continuous infusion (concentration $0.2 \mathrm{mg} \cdot \mathrm{ml}^{-1}$ ) titrated to achieve the desired level of neuromuscular blockade as monitored by the NMT. All variables were measured again at (1) $T_{4} / T_{1}$ of 0.6 and (2) maximum depression (MAX DEP) which was defined as the point when the subject became uncomfortable and did not wish further increase in weakness. All attempts were made, by careful adjustment of the infusion rate, to ensure as near steady-state condition as possible during the time of measurement. For statistical analysis, all measurements were expressed as percentages of control and comparison with controls were made using one-way ANOVA for repeated measurements and Dunnett's test. A $P$ value of less than 0.05 was considered to be significant.

\section{Results}

One subject did not complete the study and his results were excluded. The other six subjects were successfully studied without complications and none experienced any sensation of dyspoea during the study. The anthropometric characteristics of the six subjects are shown in Table $I$. Throughout the study, there was no change in $V_{T}$ in any subject. At MAX DEP, all subjects experienced difficulty with swallowing and phonation; none was able to perform any head-lift, yet all could protrude their tongues to some extent. One subject required support of the jaw to main-

TABLE II Control values and percentage change of hand-grip (HG), negative inspiratory pressure (NIP), forced vital capacity (FVC) and forced expiratory volume in one second $\left(\mathrm{FEV}_{1}\right)$ during the two levels of neuromuscular blockade studied.

\begin{tabular}{llllll}
\hline & $T_{4} / T$ & $H G$ & NIP & $F V C$ & FEV, \\
\hline Control (mean \pm SEM) & 1.0 & $272 \pm 31(\mathrm{mmHg})$ & $68 \pm 3(\mathrm{mmHg})$ & $4.38 \pm 0.33$ (litre) & $3.64 \pm 0.27$ (litre) \\
$T_{4} T_{1}^{*}$ MAX DEP & $0.21 \pm 0.05$ & $26 \pm 5 \ddagger$ & $50 \pm 6 \ddagger$ & $80 \pm 5.1 \dagger$ & $82 \pm 4.8 \dagger$ \\
$T_{4} T_{1}^{*}$ at $60 \%$ & $0.60 \pm 0.02$ & $72 \pm 12$ & $73 \pm 4 \dagger$ & $97 \pm 1.5$ & $96 \pm 2.8$ \\
\hline
\end{tabular}

*All values are per cent of control (mean \pm SEM).

$\dagger P<0.05$ vs control.

$\ddagger P<0.01$ vs control 

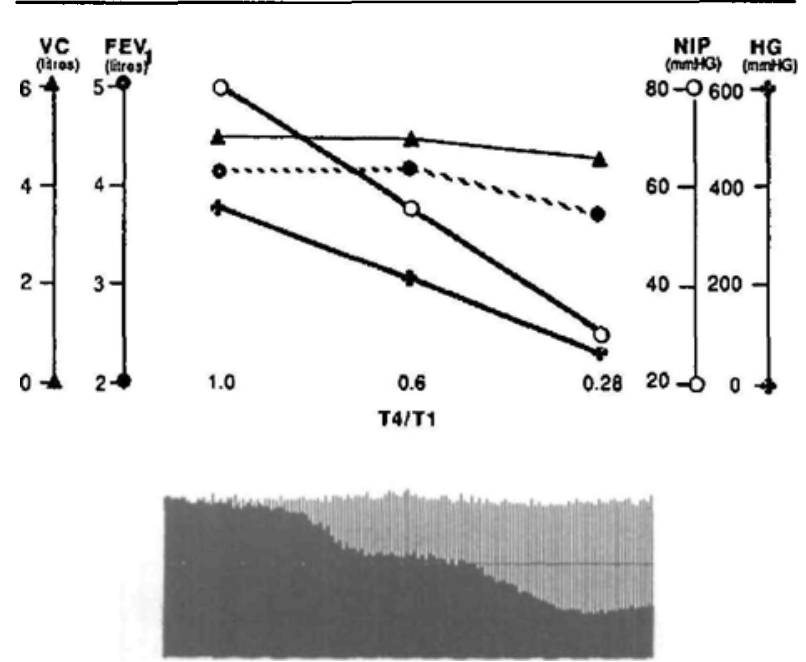

FIGURE Correlation of respiratory function and hand grip with IEEMG in one of the subjects. Assessment of vital capacity (VC), forced expiratory volume in one second $\left(F E V_{1}\right)$, maximum negative inspiratory pressure (NIP), and hand-grip (HG) are summarized above while the corresponding IEEMG tracing is displayed below. The tracing depicts both $T_{1}$ and $T_{4} E M G$ (analogous to twitch height). Before administration of atracurium, there is no fade, and $T_{4}$ is identical to and superimposed on $T_{1}$, creating the dark shade in the beginning. With onset of neuromuscular blockade, $T_{4}$ gradually declines, thus creating the dark shade $\left(T_{4}\right)$ and the light shade $\left(T_{1}\right)$.

tain a patent upper airway. There was also a significant decrease in HG, NIP, FVC and FEV, compared with baseline measurements (Table II). The mean $T_{4} / T_{1}$ ratio at the point of MAX DEP was $0.21 \pm 0.05$ ( \pm SEM). At the level of $T_{4} / T_{1}=0.6(0.60 \pm 0.02)$, all subjects were able to sustain head-lift for five seconds and maximum NIP was the only measured variable significantly depressed. The response of one subject with the corresponding IEEMG tracing is displayed in the Figure.

\section{Discussion}

Residual paralysis from the use of neuromuscular blocking agents during anaesthesia may lead to hypoventilation or upper airway obstruction and is a constant concern to the anaesthetist. Historically, several clinical tests have been utilized to assess the adequacy of neuromuscular transmission and as indirect tests of respiratory muscle function. These tests include the head-lift ${ }^{7}$ sustained for five seconds, the arm-lift test, ${ }^{16}$ the ability to protrude the tongue and the intensity of hand-grip. ${ }^{9}$ All these tests require the cooperation and coordination of an awake patient and, therefore, may not always be possible. Moreover, although the respiratory muscles are known to be more resistant than peripheral muscles, ${ }^{17-23}$ these clinical tests do not test the respiratory reserve and are not always adequate. ${ }^{1,24}$ Use of the peripheral nerve stimu- lator and observation of the mechanical twitch response provides a more objective assessment of neuromuscular transmission and is, therefore, frequently used in anaesthetic practice. A sustained twitch response to tetanic stimulation at $50 \mathrm{~Hz}$ is a good indicator for adequate return of neuromuscular transmission, and, therefore, respiratory function. ${ }^{1,25}$ However, tetanic stimulation is painful and, therefore, not applicable to awake patients.

The introduction of train-of-four stimulation, which is relatively pain-free, and the subsequent demonstration of its correlation with single twitch response ${ }^{8}$ has made such monitoring a standard practice. Studies by Ali et al. ${ }^{26-28}$ have demonstrated that a $\mathrm{T}_{4} / \mathrm{T}_{1}>0.6$ and $>0.7$ are indicative of return of adequate respiratory function in awake volunteers and anaesthetized patients respectively. However, the visual assessment of $T_{4} / T_{1}$ has been shown to be extremely unreliable with wide inter-observer variability ${ }_{+}^{29,30}$ and as yet an inexpensive, easy-to-use mechanical twitch recorder does not exist. The Datex NMT 221 monitors the IEEMG and displays the $\mathrm{T}_{1} / \mathrm{Tc}$ as well as the $T_{4} / T_{1}$ in response to train-of-four stimulation continually and is therefore an attractive alternative. ${ }^{10}$

Although baseline drift may occur and $T_{1} / \mathrm{TC}$ may not always return to 100 per cent, the $T_{4} / T_{1}$ is independent of TC and would always be available for the assessment of neuromuscular transmission. The correlation between the IEEMG and respiratory function, however, has not been determined. Since the mechanical twitch response measures the contractile response of the muscle and is, therefore, dependent on contractility and loading of the muscle, and the electromyogram measures the composite muscle action potential generated in response to depolarization of the end-plate independent of the contractile process, differences may exist between mechanical and electromyographic responses although reasonable correlation between these two modalities have been observed. ${ }^{13,14,31}$ Moreover, previous studies on respiratory function did not include the newer muscle relaxants atracurium and vecuronium and it is conceivable that their IEEMG characteristics may differ from d-tubocurarine or pancuronium although no difference apparently exists between atracurium and vecuronium. ${ }^{14} \mathrm{We}$, accordingly, designed the present study to address this issue.

We chose to record the IEEMG over the hypothenar muscle, because (1) the abductor digiti minimi is solely innervated by the ulnar nerve and (2) the relatively small movement of the muscle during contractions virtually eliminates all motion artifacts. Although classic studies on mechanical twitch response use the thenar muscles (adductor pollicis brevis) and differences between the two muscle groups may exist, the magnitude is relatively small $^{31}$ and thought to be clinically unimportant. ${ }^{14}$ These observations, however, cannot be extended to include 
other muscle groups such as the facial muscles. The respiratory variables studied are those generally used to judge whether or not a patient's trachea can be extubated. Although the peak expiratory flow rate and peak expiratory pressure may indicate the ability to cough, they are influenced by lung disease and, therefore, are not good measures of respiratory muscle strength. They are also seldom utilized as bedside measures.

Our results confirmed that respiratory muscles are more resistant to neuromuscular blockade than peripheral and pharyngeal muscles. At the level of maximum depression $\left(T_{4} / T_{1}=0.21\right)$ all subjects were unable to raise their head against the force of gravity, hand-grip was significantly depressed to 25 per cent of control, and swallowing and phonation became virtually impossible. One subject required support of his jaw to prevent upper airway obstruction. Yet all subjects maintained normal tidal volumes at control values, and although NIP was reduced to 50 per cent of control, FVC and FEV, were 80 per cent of control. At the lesser level of $T_{4} / T_{1}=0.6$, all subjects were capable of sustaining head-lift for five seconds, and the measurement of hand-grip strength, although reduced, was not significantly depressed from control values. Vital capacity and $F E V_{1}$ were equally unchanged. Despite differences in study design, i.e., IEEMG instead of mechanical twitch tension, atracurium instead of d-tubocurarine, and the supine instead of semi-recumbent position, these observations are entirely consistent with those of Ali et al. ${ }^{26}$ and indicate that a $\mathrm{T}_{4} / \mathrm{T}_{1}$ of $>0.6$ as measured with IEEMG is compatible with adequate return of respiratory muscle strength. This consistency is not surprising since (1) EMG and mechanical twitch tension are positively correlated, ${ }^{14}$ (2) atracurium and $d$ tubocurarine are qualitatively similar, and although their durations of action differ, our administration by continuous infusion minimized this difference, and (3) in non-obese subjects it is unlikely that the change in respiratory function with subclinical paralysis would differ significantly between the supine and semirecumbent position. Moreover, Gal and Goldberg ${ }^{32}$ had previously observed that the percentage reductions in force for curarized muscles were approximately the same at all lung volumes, so any difference in lung volume between the two body positions should have no effect on our findings. Corroborating our findings, these authors also found that, in their partially curarized supine subjects, a normal vital capacity could be associated with a slightly reduced inspiratory pressure. ${ }^{32}$

Several other points deserved comment. Maximum negative inspiratory pressure, although averaged at 73 per cent of control when $T_{4} / T_{1}=0.6$, was significantly reduced. We suspect this was not due to respiratory muscle weakness, but rather from weakness of pharyn- geal muscles and/or vocal cord paresis leading to a partial airway obstruction during maximal forced inspiration. That upper airway obstruction may exist during partial paralysis had been demonstrated in previous studies utilizing various flow volume loops, ${ }^{18}$ peak inspiratory flow, ${ }^{33}$ maximum voluntary ventilation, ${ }^{17}$ and upper airway resistance measurement.* More recently, Pavlin et al. ${ }^{34}$ reported that a NIP exceeding (more negative than) $50 \mathrm{mmHg}$ is required to overcome upper airway obstruction, and is consistent with our observations. However, the clinical significance of such a small reduction in NIP remains to be established; at this level, the lowest NIP in our subjects was $45 \mathrm{mmHg}$ and far exceeded the usual

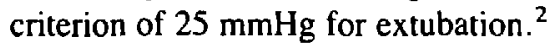

We may be criticized for studying the respiratory function during steady-state infusion rather than during recovery as occurs in clinical practice. The short-acting nature of atracurium simply does not allow execution of the measurements during a rapid recovery phase: Moreover, any potential bias introduced by this experimental design would only serve to overestimate the respiratory impairment as steady improvement can be expected after $\mathrm{T}_{4} / \mathrm{T}_{1}$ reaches 0.6 during recovery from atracurium blockade.

Kopman has previously reported that mechanical twitch $T_{4} / T_{1}$ lags behind IEEMG during recovery from atracurium blockade. " Should this relationship hold true for our observations, our IEEMG $T_{4} / T_{1}$ of 0.6 would translate to a lower value in mechanical response and, therefore, would be inconsistent with Ali's observations. However, important differences exist between Kopman's study and our study; Kopman's patients were studied during halothane-nitrous oxide anaesthesia while our subjects were awake. Moreover, it has been reported that IEEMG $T_{4} / T_{1}$ is virtually identical to the mechanical response during onset of atracurium ${ }^{12}$ although IEEMG similarly lags behind during recovery. As our experimental design compares more closely to onset rather than recovery, the $T_{4} / T_{1}$ likely approximates the mechanical counterpart. The strength of peripheral muscles as assessed by HG and head-lift further lend support to our observations on respiratory function. However, in stating that an IEEMG $T_{4} / T_{1}$ of 0.6 is compatible with near normal respiratory function, it must be emphasized that our subjects were unanaesthetized, and had not undergone surgical procedures. The validity of using IEEMG $T_{4} / T_{1}$ of 0.6 as an indicator of adequate return of respiratory function in anaesthetized patients, therefore, remains to be confirmed. In this context, we would agree with

\footnotetext{
*Dodgson BG, Knill RL, Clement $J L$ (Abstr). Curare increases upper airway resistance while reducing ventilatory muscle strength. Can Anaesth Soc J 1981; 28: 505-6.
} 
Kopman's statement that an IEEMG $\mathrm{T}_{4} / \mathrm{T}_{1}$ of $>0.9$ would ensure adequate return of neuromuscular function, even if this value seems unnecessarily high judging from our observations. We also confirmed that the NMT monitor is easy to use and its employment in clinical practice allows continuous quantitative assessment of the neuromuscular function and may improve patient safety.

In conclusion, we have observed that ( 1 ) in unanaesthetized subjects, an IEEMG $\mathrm{T}_{4} / \mathrm{T}_{1}$ of 0.6 is consistent with nearly normal respiratory function, (2) significant respiratory impairment can exist without a reduction in tidal volume, and (3) as observed by others, upper airway obstruction may be an important factor in patients with residual neuromuscular blockade.

\section{Acknowledgements}

The authors thank Ms. Jane Clement for technical assistance, and Mrs. Valerie Rapson and Mrs. Shawn Shaffer for secretarial assistance.

\section{References}

1 Walts $L F$, Levin N, Dillon JB. Assessment of recovery from curare. JAMA 1970; 213: 1894-6.

2 Bendixen HH, Surtees AD, Oyama T, Bunker J.P. Postoperative disturbances in ventilation following the use of muscle relaxants in anesthesia. Anesthesiology 1959; 20: $121-2$.

3 Ali $H H$. A new device for monitoring force of thumb adduction. Br J Anacsth 1970; 42: 83-5.

4 Ali $H H$, Utting JE, Gray TC. Quantitative assessment of residual antidepolarizing block (Part I). Br J Anaesth 1971; 43: 473-6.

5 Churchill-Davidson HC, Christie TH. The diagnosis of neuromuscular block in man. Br J Anaesth 1959; 31: 290-301.

6 Katz $R L$. A nerve stimulator for the continous monitoring of muscle relaxant action. Anesthesiology 1965; 26: 832-3.

7 Ali HH, Utting JE, Gray TC. Quantitative assessment of residual antidepolarizing block (Part II). Br J Anacsth 1971; 43: 478-85.

8 Lee $C M$. Train-of-4 quantitation of competitive neuromuscular block. Anesth Analg 1975; 54: 649-53.

9 Viby-Mogensen $J$. Clinical assessment of neuromuscular transmission. Br J Anaesth 1982; 54: 209-23.

10 Carter JA, Arnold R, Yate PM, Flynn PJ. Assessment of the Datex rclaxograph during anaesthesia and atracurium-induced neuromuscular blockade. $\mathrm{Br} \mathrm{J}$ Anaesth 1986; 58: 1447-52.

11 Lam $\mathrm{HS}$, Cass $\mathrm{NM}, \mathrm{Ng} \mathrm{KC}$. Electromyographic monitoring of neuromuscular block. Br J Anaesth 1981; 53 . 1351-7.
12 Pugh ND, Kay B, Healy TEJ. Electromyography in anacsthesia. Anaesthesia 1984; 39: 574-7.

13 Kopman AF. The relationship of evoked electromyographic and mechanical responses following atracurium in humans. Anesthesiology 1985; 63: 208-11.

14 Weber $S$, Muravchick $S$. Electrical and mechanical trainof-four responses during depolarizing and nondepolarizing neuromuscular blockade. Anesth Analg 1986 65: 771-6.

15 Helewa, A, Goldsmith $C H$, Smythe HA. The modified sphygmomanometer - an instrument to measure strength: a validation study. J Chronic Dis 1981; 34: 35361 .

16 Bar ZG. The armlift test. Anacsthesia 1985; 40:630-3.

$17 \mathrm{Gal} \mathrm{TJ}$, Goldberg $S K$. Diaphragmatic function in healthy subjects during partial curarization. J Appl Physiol 1980; 48: 921-6.

$18 \mathrm{Gal}$ TJ, Arora NS. Respiratory mechanics in supine subjects during progressive partial curarization. J Appl Physiol 1982; 52: 57-63.

19 DeTroyer A, Bastenier J, Delhez L. Function of respiratory muscles during partial curarization in humans. J Appl Physiol 1980; 49: 1049-56.

20 Rosenbaum SH, Askanazi J, Hymann AL, Kinney $J M$. Breathing pattems during curare-induced musclc weakness. Anesth Analg 1983; 62: 809-14.

21 Foldes FF, Monte AP, Brunn HM, Wofson B. Studies with muscle relaxants in unanaesthetized subjects. Anesthesiology 1961; 22: 230-6.

22 Waud $B E$, Waud DR. The margin of safety of neuromuscular transmission in the muscle of the diaphragm. Anesthesiology 1971; 37: 417-22.

23 Wymore ML, Eisele JH. Differential effects of d-tubocurarine on inspiratory muscles and two peripheral muscle groups in anesthetized man. Anesthesiology 1978; 48: 360-2.

24 Viby-Mogensen J, Jorgensen BC, Ording $H$. Residual curarization in the recovery room. Anesthesiology 1972; 37: 417-22.

25 Ali HH, Savarese JJ, Lebowitz PW, Ramsey FM. Twitch, tetanus, and train-of-four as indices of recovery from nondepolarizing neuromuscular blockade. Anesthesiology 1981; 54: 294-7.

26 Ali HH, Wilson RS, Savarese JJ, Kitz RJ. The effect of tubocurarine on indirectly elicited train-of-four muscle responses and respiratory measurements in humans. $\mathrm{Br} \mathrm{J}$ Anaesth 1975; 47: 570-3.

27 Brand JB, Cullen DJ, Wilson NE, Ali HH. Spontaneous recovery from non-depolarizing neuromuscular blockade: correlation between clinical and evoked responses Anesth Analg 1977; 56: 55-8.

28 Ali $H H$, Kilz $R J$. Evaluation of recovery from nondepolarizing neuromuscular block, using digital neuro- 
muscular transmission analyzer: preliminary report. Anesth Analg 1973; 52: 740-4.

29 Viby-Mogensen J, Jensen NH, Engbaek J, Ording H, Skovgaard LT, Chraemmer-Jorgensen $B$. Tactile and visual evaluation of the response to train-of-four nerve stimulation. Anesthesiology 1985; 63: 440-3.

30 Donati F, Bevan JC, Bevan DR. Neuromuscular blocking drugs in anaesthesia. Can Anaesth Soc J 1984; 31: 324-6.

31 Katz $R L$. Electromyographic and mechanical effects of suxamethonium and tubocurarine on twitch, tetanic and post-tetanic responses. Br J Anaesth 1973; 45: 849-59.

32 Gal TJ, Goldberg SK. Relationship between respiratory muscle strength and vital capacity during partial curarization in awake subjects. Anesthesiology 1981; 54: 141-7.

33 Johansen SH, Jorgensen $M$, Molbech S. Effect of tubocurarine on respiratory and non-respiratory muscle power in man. J Appl Physiol 1964; 19: 990-4.

34 Pavlin EG, Holle RH, Schoene RB. Recovery of airway protection compared with ventilation in humans after paralysis with curare. Anesthesiology 1989; 70: 381-5. 